\title{
Building archaeology geodatabase in Iraq using GIS
}

\author{
Abbas Kalaf ${ }^{1}$, Hisham Al Sharaa ${ }^{1, *}$, Israa Hatem ${ }^{1}$, and Hussein Mohammed ${ }^{1}$ \\ ${ }^{1}$ Building and Construction Department, University of Technology, Baghdad, Iraq
}

\begin{abstract}
Geomatics has been an important tool in archaeology. The combination of Geomatics and archaeology adopters have been considered a perfect match, since archaeology often involves the study of the spatial dimension of human behavior over time, and all archaeology carries a spatial component. Since Iraqi archaeology becomes one of the main victims of destruction by negligence and terror attacks, makes our great heritages forgotten. Hence, it is necessary to build a secure database for all Iraqi archeological sites with their two main types (investigated and uninvestigated) and rely on digital system by creating digital maps for each Governorate with their archeological database system. Results of archaeological studies are rich in spatial information. GIS is adept at processing these large volumes of data especially those that are geographically referenced. It is effective, accurate and a fast tool. The tools made available through GIS help in data collection, its storage and retrieval, its ability for customization and, finally, the display of the data so that it is visually comprehensible by the user. The most important aspect of GIS in archaeology lies, however, not in its use as a pure map-making tool, but in its capability to merge and analyze
\end{abstract}

\section{Introduction}

The Iraqi archeology with all its classifications is one of the most important sources of historical information. Therefore, this research focuses on the adopters its effects and saving this heritage. Iraq possesses a large percentage of these monuments, including the civilization of Ur and Babylon, as well as the existence of many sites and archaeological remains; Iraq is a symbol of great cultural prosperity. From this simple description, the need to introduce modern digital techniques from geomatics has become urgent in an attempt to manage the databases of Iraqi archeological sites and use them in the correct geometric form to prevent them from loss. The objective of mapping archaeological sites is to ensure that, they are not affected, and spatial database can be updated and analysed easily.

This research includes an overview of the spatial data problem of any project accomplished using digital techniques in geomatics in terms of combination, geometrical correction and spatial data links and display by information such as the numerical objective station. This will contain the collection of data needed for this subject of the project after the processing of sources. In addition, Maps, satellite images of the study area and raw spatial data collected are then processed and equipped to prepare spatial databases.
The problem is in the abundance and dispersion of data pertaining to all Iraqi archeology sites, gaps in database documentation for many years, dependence on paper documentation and Excel program, which are prone to loss and damage and are not easy to use / refer to them. The field survey for the archeology sites around the country presents the scarcity of documentation and updating of the geographical information of these archaeological sites for several years, during which the site changes due to changing weather conditions, which can cause sites location, to be lost, especially non-prospecting sites.

\section{Area of interest}

The study area covers the whole of Iraq from east to west and from north to south. Iraq is located in the heart of the ancient and modern world. Iraq is located within three zones $(37,38$ and 39). Its center is Baghdad, which is located at $45^{\circ}$ longitude $\mathrm{E}$ and $33^{\circ}$ latitude N. Iraq is bordered by Turkey (Anatolia) in the north, Iran (Persia) in the east, Kuwait and Saudi Arabia (the Arabian Peninsula) in the south and Jordan and Syria (Levant) in the west. The governorates of Dhi Qar and Qadissiya were selected as study area for the research output spatial data and within the archaeological sites surveys for the year 2010-2015.

\section{Problem statement}

\footnotetext{
*Corresponding author: hishamalsharaa@live.com
} 


\section{Methodology}

The theoretical aspect of collecting descriptive data from multiple sources, official departments and field surveys, as well as spatial data collection to use them in spatial information techniques to arrange and organize these data both spatially and descriptively as a practical aspect by constructing a spatial database using ArcGIS 10.3 for building and analysing the existing archaeological sites.

\section{Geomatics Techniques}

There are many techniques involved in the field of geomatics. However, in this paper a brief explanation of the theoretical part of digitalizing, its contribution, preparation and construction of spatial databases, framed to find a digital system that will be reliable in all spatial analysis, and will represent the best way to achieve any engineering goal.

These techniques can based on how spatial databases are prepared based on:

1. Display data and digital processing software.

2. Geographic information systems.

3. Maps.

4. Satellite system.

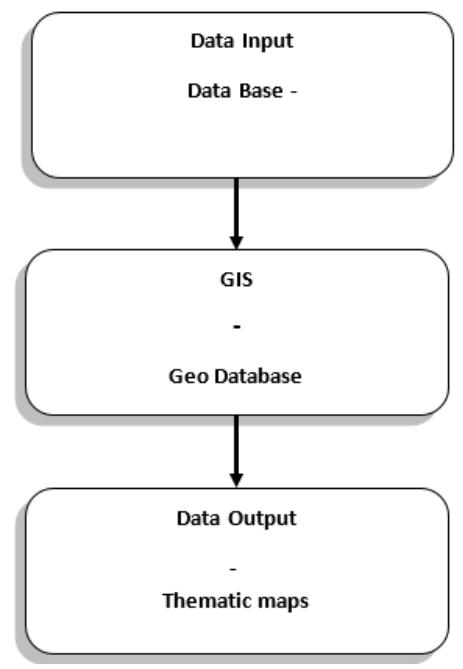

Fig. 1. Database building system

\section{Spatial Geo Database}

One important term in GIS system is the installation of geographical locations of the archaeological sites precisely by using Global Positioning System (GPS). Because of the difficulties to reach some archaeological sites, the researcher entered the coordinates sent by the Archaeological Authority in each Governorate to the General Archaeological Authority and converted these coordinates to maps and turned them into databases containing location data. This will help in terms of better and faster decision-making, lesser conflicts related to infrastructure sites and taboos, leading to lesser changes in the selection of project sites and objective production of maps using the information available in the database.

\subsection{Steps to build a spatial geodatabase:}

The spatial database is built using Arc Catalog, which is part of the ArcGIS10.3 software package, where the project database is prepared according to the Geographical Coordinate System and the WGS84 support platform and WGS84.

The database was designed according to standard specifications as shown in the figure (2).

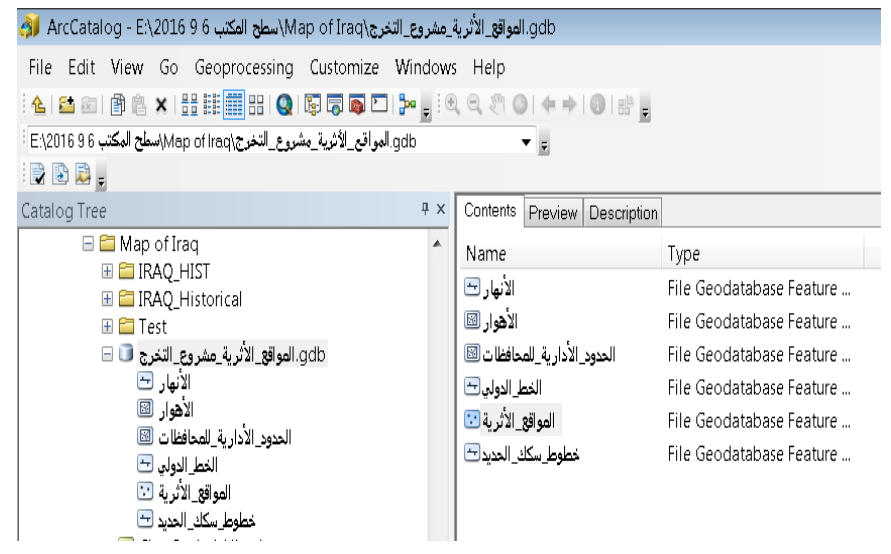

Fig. 2. Steps to build a spatial geodatabase

The Draw points represent the effects depending on the boundaries of the provinces using the ArcMAP program and the distribution of points by archaeological sites, taking into account the name of the archaeological site on each point as shown in Figure (2\&3).

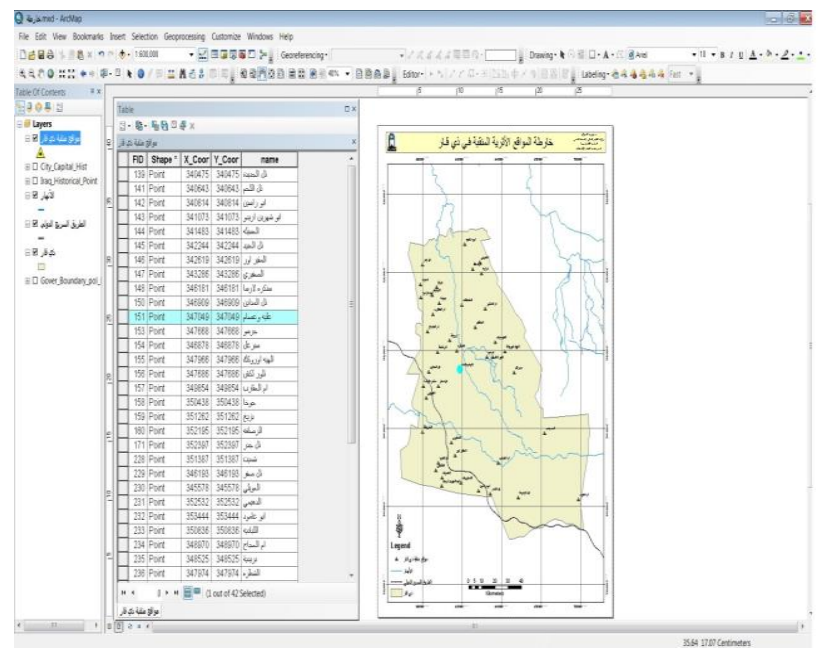

Fig. 3. The descriptive table of the archaeological attribute site 


\section{Maps Generations}

The map below shows all points of archeology after completion of the process of drawing points representing the effects distributed across the provinces

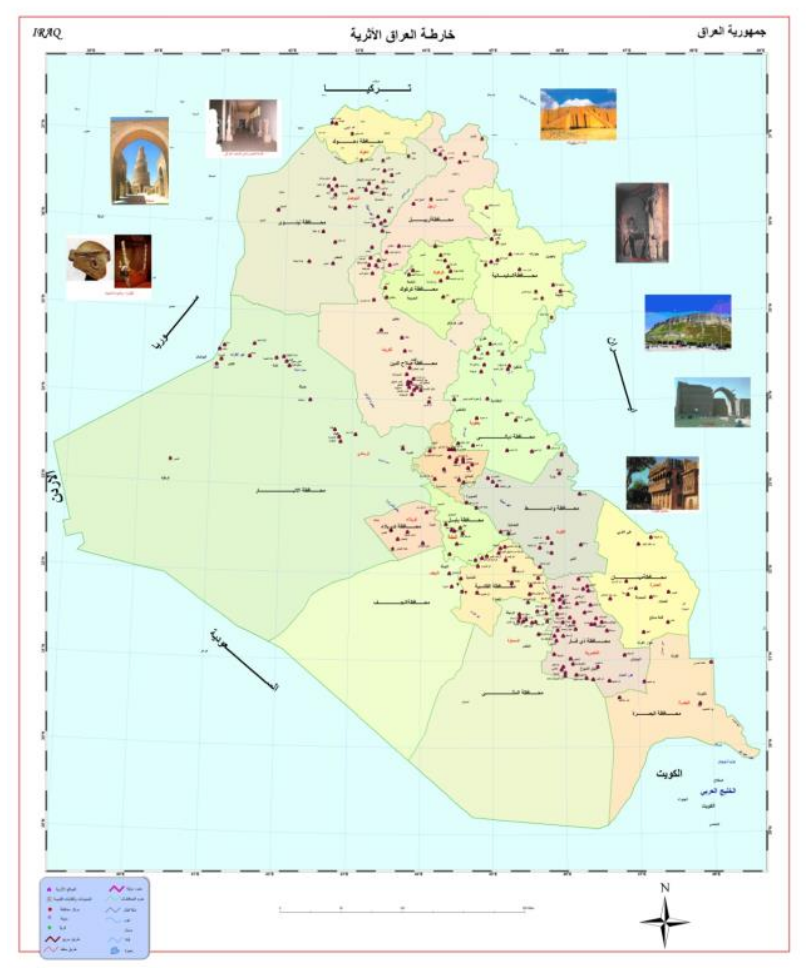

Fig. 4. Complete the process of drawing points that represent the archaeology sites

\section{Topology}

\subsection{Process}

This process is the topological correction stage, which is considered one of the important stages in the process of drawing and preparing the geographical data base and is necessary in all the work of geographic information systems. It is the process of organizing spatial relations and dealing with all the problems and overlaps that occur between the different layers in the geographic data base, which are organized using special parameters to be installed during the preparation of the spatial database.. For this purpose, it is necessary not to overlap the symptoms drawn with each other for administrative boundaries. For example, the borders of the Governorate of Nazareth should not interfere with any of the borders of the neighboring governorates. (Must not Have Gaps) This parameter is necessary to avoid gaps during the process of drawing the symptoms of the administrative boundary, for example, they should not make a gap between the boundaries of the province and other Governorate needs to be adjacent without interference. This is meant to be the point of the effects within the boundary of the administrative boundary layer, in other words it must not be located outside the administrative boundaries of the provinces as it does not use the other determinants because the class effects of the points in the geometric shape do not need other determinants. The process of checking and detecting errors: After completing the process of entering the parameters of the Topology process, we use another program, the Arc MAP program for the purpose of auditing and detection of errors and overlaps are identified in the process of adding parameters using the tool Topology Tools. By using Error Inspector, errors, if any, are detected in the graphics, and are handled and corrected and the changes are stored on the original layer, whether the administrative boundary or the layer effects and then the layers are ready for the process of display in maps or in the digital versions.

\subsection{Output}

After the completion of preparing the geographical data base in its final form, it is possible to display the information that was entered in multiple formats according to the need. The final output is objective specific for each possible effect, can be extracted in the form of maps or any files when clicking on any effect. The entrance to the system enables all information and offers advantage of the search feature and query in ArcGIS program in the search for the impact of a particular Auadh effects as well as possible sort effects by prospecting and by the excavating and by Governorate will show ... etc any in general, the database is characterized by flexibility and oversight $\mathrm{E}$ dealt with where the researcher produce thematic maps concerning the effects of which will be mentioned below.

\section{Results and desiccations}

Production of a map for the undeclared effects of Dhi Qar Governorate according to the 2010 surveys and using the quadratic coordinate system according to Figure (5).Production of objective maps derived from the map of the distribution of antiquities Figure (6) below shows the production of a thematic map of the archaeological sites declared in the province of Qadisiyah.

Production of objective maps showing the distribution of the effects in Qadisiyah Governorate Figure (7) below Production of a thematic map concerning archaeological sites in Qadisiyah Governorate and Production of full geodatabase system as illustrated in Figure (8). 


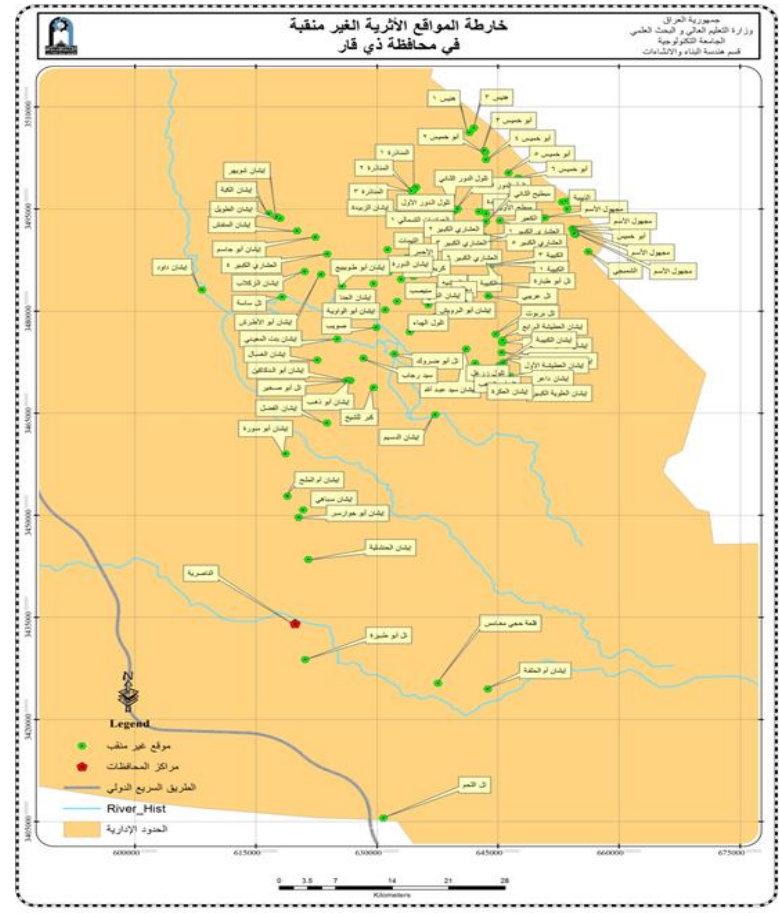

Fig. 5. Map of the undiscovered archaeological sites of Dhi Qar governorate according to the 2010 survey

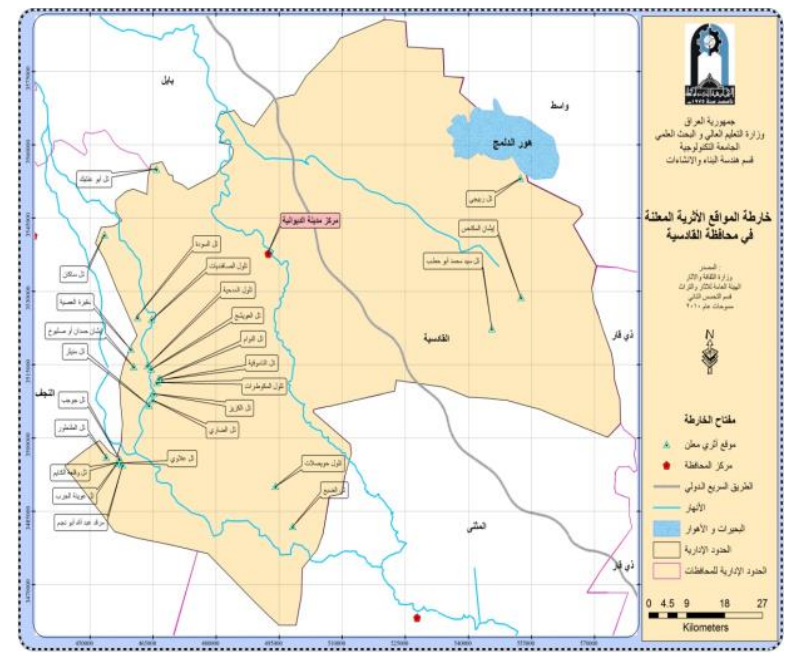

Fig. 6. Production of a thematic map concerning the archaeological sites declared in Qadisiyah governorate

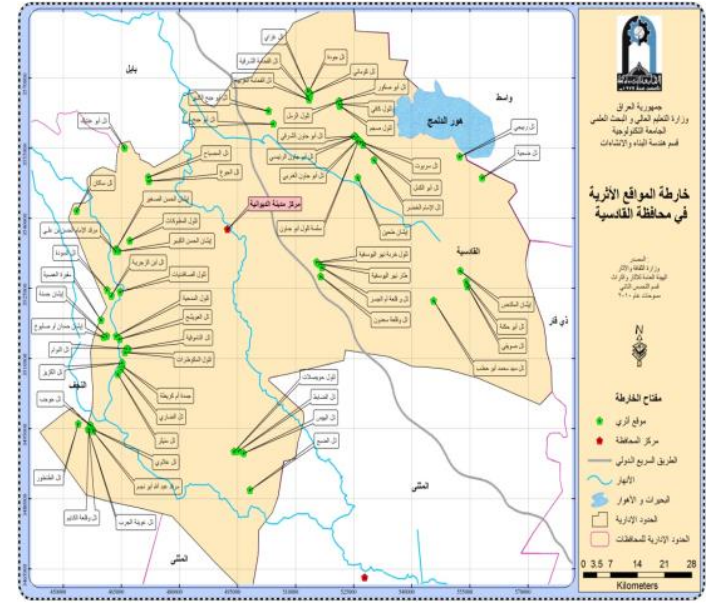

Fig. 7. Production of a thematic map concerning archaeological sites in Qadisiyah governorate

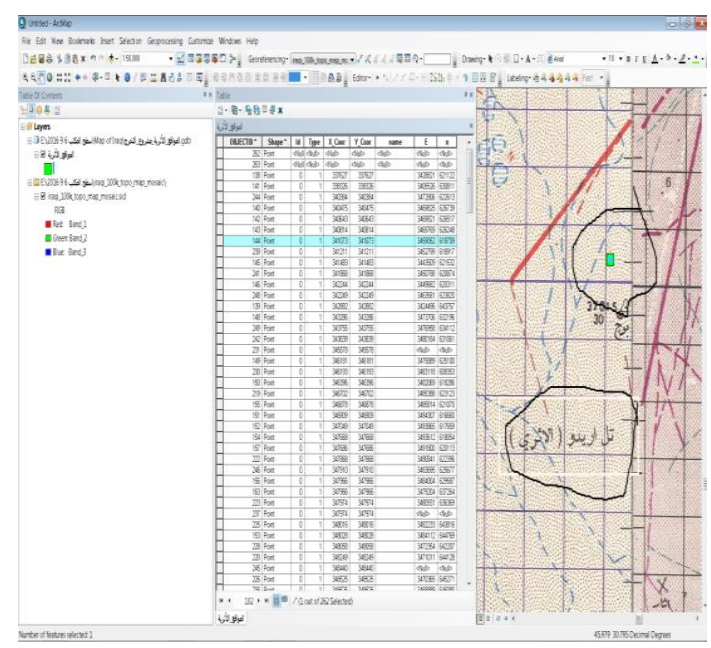

Fig. 8. Production of full geodatabase system

\section{Conclusions}

1. The maps produced on Iraqi provinces illustrated the excavated archaeological areas.

2. Many archaeological sites are undeveloped and unprotected.

3. Weak statistics and follow-up of data collection by the relevant authorities, which negatively affect the process of input, analysis and production.

4. The high possibility of GIS programs in the field of measuring distances and spaces and high-resolution, geographical locations and in the coding and coloring. The final output maps are in a manner impossible to achieve by traditional methods.

5. The presence of some areas of relics within the submerged marshes.

6. The possibility of preparing a geographic database by the GIS, regardless of size and storage within the computer and then referring to them at any time and making adjustments to them according to the latest changes result in high accuracy in a very short time compared to the traditional methods and then producing 
maps showing any recent change in the study area.

7. The accuracy of the spatial data of archaeological sites sent to the General Authority for Antiquities was observed. There is a creep in the coordinates of the site between geographical coordinates and square.

8. It is possible to benefit greatly from the geographical phenomena plotted by the GIS programs after the establishment of the database to install them together and find spatial relations between them, impact each other through the spatial analysis of the same program and the production of new maps.

\section{Recommendations}

1. Control the indiscriminate construction and prevent excesses on uninhabited areas by the state and to follow modern techniques in prospecting.

2. The use of geographic information systems (GIS) programs in many analytical methods to produce digital analytical maps of many phenomena that are of interest to decision makers.

3. The use of GIS programs to produce all the maps needed by planners, researchers and decision makers according to the built-in database such as using the ARCGIS software to produce thematic maps and all maps according to user needs and coordinates and updating them.

4. Building geographic databases that contain urban architectural data and keep them up-todate.

5. For the purpose of increasing the accuracy of the produced map, it is preferable to use modern, correct and high-resolution satellite images, by increasing accuracy, determining the projection system, coordinates and conducting the geo-referencing process.

6. Choose the appropriate method to connect the AutoCAD drawings drawn above the corrected spatial images of the required study area and perform the geo-referencing process to minimize or eliminate errors resulting from the linkage such as crawling based on GPS ground control points.

7. Adopting real coordinates at the drawing using Autocad using the corrected images of the study area and converting the Autocad maps to the ARC GIS programs to obtain the required accuracy and facilitate the work to build a geographical database containing all data and information belonging to the study area.

8. The production of three-dimensional maps of the archaeological areas and the construction of geographical databases containing all the contents of the place of built areas and areas and internal methods as well as building materials used and build a database of all the contents of the explanatory and conduct analysis and linking parameters and conduct relationships in the future.

9. Updating land surveys of archaeological areas and adopting this as a national project to preserve the cultural history of Iraq.

\section{References}

1. Hussein H.M. "Building Archaeology Geodatabase in Iraq Using GIS," (UOT, 2016).

2. H. M.J. Al Sharaa, J. Eng. Sustain. Dev.,20,113(2016) 